\title{
Impact of patient handover structure on neonatal perioperative safety
}

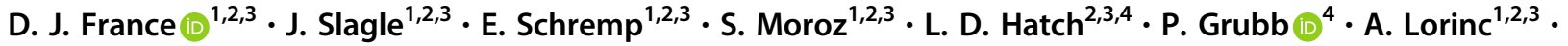

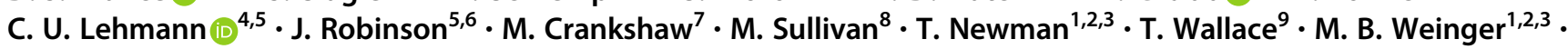 \\ M. L. Blakely ${ }^{6}$
}

Received: 18 September 2018 / Revised: 7 December 2018 / Accepted: 13 December 2018 / Published online: 17 January 2019

(c) Springer Nature America, Inc. 2019

\begin{abstract}
Objective To compare the incidence, severity, preventability, and contributing factors of non-routine events-deviations from optimal care based on the clinical situation-associated with team-based, nurse-to-nurse, and mixed handovers in a large cohort of surgical neonates.

Study design A prospective observational study and one-time cross-sectional provider survey were conducted at one urban academic children's hospital. 130 non-cardiac surgical cases in 109 neonates who received pre- and post-operative NICU care.

Results The incidence of clinician-reported NREs was high (101/130 cases, 78\%) but did not differ significantly across acuity-tailored neonatal handover practices. National Surgical Quality Improvement-Pediatric occurrences of major morbidity were significantly higher $(p<0.001)$ in direct team handovers than indirect nursing or mixed handovers.

Conclusions NREs occur at a high rate and are of variable severity in neonatal perioperative care. NRE rates and contributory factors were homogenous across handover types. Surveyed clinicians recommend structured handovers for all patients at every transfer point regardless of acuity.
\end{abstract}

D. J. France

dan.france@vumc.org

1 Department of Anesthesiology, Vanderbilt University Medical Center, Nashville, TN, USA

2 Center for Research and Innovation in Systems Safety, Vanderbilt University Medical Center, Nashville, TN, USA

3 Department of Pediatrics, Division of Neonatology, Monroe Carell Jr. Children's Hospital at Vanderbilt, Nashville, TN, USA

4 Department of Pediatrics, Division of Neonatology, Primary Children's Hospital, University of Utah, Salt Lake City, UT, USA

5 Department of Biomedical Informatics, Vanderbilt University Medical Center, Nashville, TN, USA

6 Department of Pediatric Surgery, Monroe Carell Jr. Children's Hospital at Vanderbilt, Nashville, TN, USA

7 Neonatal Intensive Care Unit, Monroe Carell Jr. Children's Hospital at Vanderbilt, Nashville, TN, USA

8 Perioperative Services, Vanderbilt University Medical Center, Nashville, TN, USA

9 Neonatal Intensive Care Unit, Nationwide Children's Hospital, Columbus, $\mathrm{OH}$, USA

\section{Introduction}

Patient handovers, the process of transferring primary authority for clinical care from one caregiver (or group of caregivers) to another [1], are ubiquitous in medicine, and an essential feature of the management of surgical patients in the neonatal intensive care unit (NICU). While common, handovers present both a threat to patient safety and an opportunity to develop processes to foster communication and teamwork, thereby improving safety risk.

Different handover structures exist with potentially different effects on patient safety. Interdisciplinary, team-based handovers consist of all personnel on the current care team (e.g., physicians, nurses, respiratory therapists, etc.) providing care transition to an interdisciplinary group of team members receiving the infant for a new phase of care. These interdisciplinary, team-based handovers have been shown to improve the safety, efficiency, and quality of care transitions between intensive care units and operating rooms (ORs) primarily in adults [2-5]. Despite their benefits, the safety risks that persist for team-based handovers have not been adequately defined, especially in pre-operative neonatal 
settings. Alternatively, nursing-based handovers, consisting of nurse-to-nurse handover only, remain the most prevalent form of handover in many NICUs and perioperative environments due in part to their ease of implementation $[1,6,7]$. No studies have systematically evaluated the effect of handover type (team-based versus nursing-based) on patient safety risk in critically ill neonates.

Hospitalized neonates, especially those with surgical pathologies, are one of the highest risk groups for iatrogenic events due to their size, fragility, unique developmental physiology, inability to communicate verbally, and sensitivity to environmental stressors [8]. Rates of adverse events, such as medication errors and adverse drug events, are as much as 8 times higher for NICU patients compared with hospitalized adults [9]. Safety risks may be greatest during and surrounding surgery, yet there is very little published data on the perioperative safety of surgical neonates. An analysis of 2012 National Surgical Quality Improvement Program Pediatric (NSQIP-P) data found that neonates represented only $6 \%$ of all patients, yet accounted for 60 and $16 \%$ of the total observed 30-day post-operative morbidity and mortality, respectively [10]. Unadjusted mortality (2-3\%) and composite morbidity (16-21\%) rates are as much as two-fold higher for neonatal versus pediatric surgery patients in all specialties except orthopedics $[11,12]$. The relative contribution of medical errors, such as those that occur in association with handovers, to these outcomes remains largely unknown.

The primary objective of this study was to evaluate the impact of handover structure on patient safety risk during the perioperative period in a cohort of surgical neonates, arguably the most vulnerable population of hospitalized patients. To do this, we used the non-routine events (NREs) methodology, a novel method of capturing risk that has been used in high-reliability industries such aviation and nuclear power [13-15]. An NRE is any event that is perceived by care providers or skilled observers as a deviation from optimal care based on the clinical situation [13].

\section{Methods}

\section{Design and setting}

We conducted a 17-month prospective mixed-methods observational study at an urban academic children's hospital to assess the incidence and etiology of NREs during neonatal perioperative care and to define factors (e.g., handovers) that were associated with NRE incidence and severity.

The primary unit of analysis was a 'case', which consisted of four phases: (1) the pre-operative phase, defined as the period (up to one hour) before the patient (i.e., neonate) left the NICU and the departing transfer from the NICU to the OR; (2) the OR phase, defined as the period starting with the patient's entry into the OR and ending with their exit from the OR, including the operative procedure(s); (3) the early post-operative phase, which included the patient's transport from the OR to the post-anesthesia care unit (PACU) or NICU, any post-operative handovers, and the first hour of post-operative NICU care; and (4) the late postoperative phase, defined as the $24 \mathrm{~h}$ that followed the early post-operative phase. Trained research assistants (RAs) surveyed NICU and OR providers after each perioperative phase, using a previously validated instrument to collect information on the incidence, severity, and preventability of NREs and their contributory factors [13]. NSQIP-P occurrences were identified through structured chart review.

A one-time 30-item cross-sectional survey of providers' perceptions and attitudes about the study hospital's current handover practices was administered at month 15 of the 17month study period.

\section{Participants}

The study protocol was approved by the Vanderbilt University Institutional Review Board. Eligible neonates had to be admitted to the NICU, receive pre-operative care in the NICU, were scheduled to undergo non-cardiac surgery (in either the OR or NICU), and were expected to receive postoperative NICU care. Convenience sampling was used to identify eligible patient who had scheduled or emergency operations during weekday hours (i.e., $7 \mathrm{am}$ to $6 \mathrm{pm}$ ). The study was powered to determine the association between NREs and NSQIP-occurrences in surgical neonates using an estimate of the neonatal perioperative NRE incidence rate collected in pilot studies along with the hospital's historical NSQIP-P occurrence rates. Eligible patients were excluded if study personnel were unable to obtain written informed consent from the parent/legal guardian, from at least one clinician in each perioperative phase, or if the infant's surgical procedure was not eligible for NSQIP-P review.

All perioperative providers, $(n=634)$ including attending physicians, fellows, residents, nurses, nurse practitioners, therapists (respiratory, occupational, etc.), technicians, and clinical staff who deliver care to neonates, were eligible to participate in the observational study and the cross-sectional survey. Providers were required to provide written informed consent quarterly during the study period and verbal consent prior to each enrolled case. There was a separate written informed consent associated with the web-based survey.

\section{Patient transfer and handover processes}

The study hospital used different perioperative transfer processes, as dictated primarily by patient acuity. Critically 


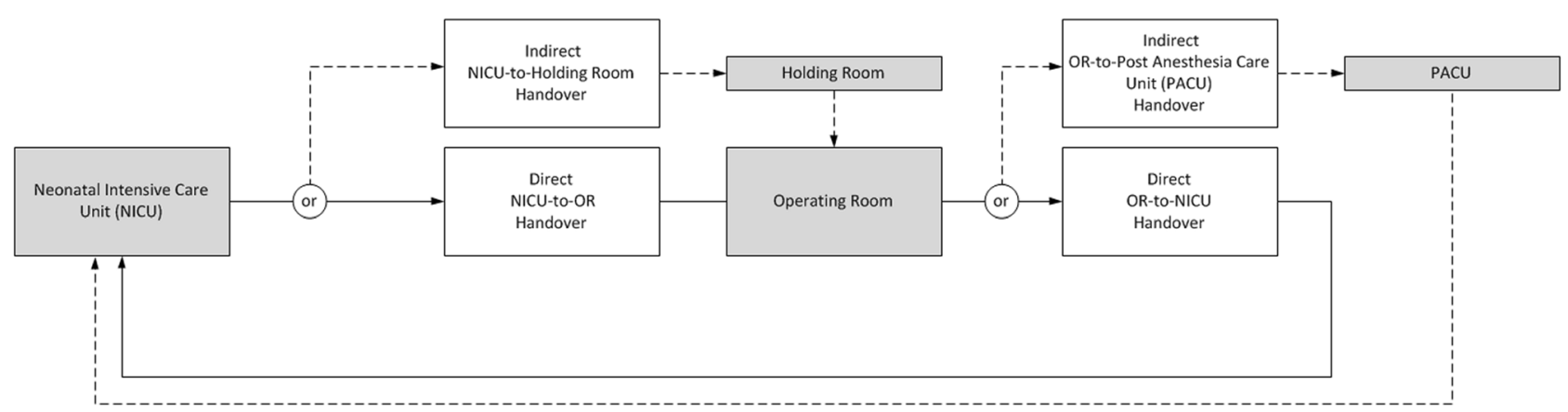

Fig. 1 Direct and indirect perioperative handovers

ill neonates (mechanically ventilated, high levels of noninvasive respiratory support) were transferred from the NICU directly to the OR (direct) while less acute patients were transferred from the NICU to the preoperative holding area (indirect) before going into the OR. Similarly, postoperative neonates were either transferred directly back to the NICU (direct) or first to the PACU before later being transferred to the NICU (indirect). The hospital developed specific patient handover practices for each perioperative transfer processes (Fig. 1) Direct transfers were almost exclusively associated with a structured, interdisciplinary, team-based, face-to-face handover (i.e., direct handover) between the responsible teams transferring care. At a minimum, direct handovers required the presence and participation of the anesthesia provider and the NICU nurse but much broader participation from neonatology, anesthesia, pediatric surgery, perioperative services, and parents/legal guardians was encouraged. Their content and structure was developed as a part of prior intensive quality improvement (QI) initiative between Anesthesiology, Neonatology, and Pediatric Surgery. During this initiative, perioperative clinicians received formal training on the handover process and their performance was evaluated by trained observers. Upon the completion of the QI initiative, the direct handover process was adopted as the standard approach for critically ill neonates and remains so today.

In contrast, handovers for indirect transfers (i.e., indirect handovers) were conducted between NICU and OR nurses, were not standardized, and often occurred via phone.

Providers received no formal training for indirect patient handovers.

Perioperative teams used a mixed handover process for neonates who required low respiratory support preoperatively (i.e., indirect transfer) and high respiratory support post-operatively (i.e., direct transfer).

The discussion of pre-operative and post-operative events was a standard component of handover practices at the study hospital prior to and during the study period. These events were typically serious near misses or events that resulted in patient harm or significant changes in the perioperative care plans. However, the term "non-routine event", which incorporates a broader range of events than serious near misses and adverse events, had not been formally incorporated into the language of the direct handover script or recommended as a topic of discussion in indirect or mixed handovers prior to the initiation of the study. Since the study's primary objective was to characterize neonatal risk in the context of current perioperative patient handover practices, NRE reporting and discussions were not specifically addressed in any way during observed handovers.

\section{Measurement of handover effectiveness}

The Handover Evaluation Instrument's Global Rating of Handover Effectiveness, a validated handover evaluation instrument [16], was used by RAs to score the completeness of information exchange, the quality of interpersonal communications, and the overall effectiveness of direct handovers. This tool (Range: 1 (minimum) to 5 (maximum)) was originally developed and validated during a study to improve OR-to-PACU handovers for adult and pediatric patients. As in that study, a value of three or greater was considered an effective handover [16]. The effectiveness of unstructured indirect handovers was not scored by RAs. In the case of mixed handovers, RAs only scored the effectiveness of the direct handover component.

\section{NRE measurement}

Non-routine events (including incidence rates and severity) were the primary outcome measure in this study. Research assistants collected NRE reports from perioperative clinicians after each perioperative phase using the Comprehensive Open-Ended Non-Routine Event Survey (CONES), which has been described previously [13]. Using the CONES, clinicians rated the severity of NREs on a 5-point Likert-like scale (1 (negligible), 3 (moderate severity), 5 (catastrophic)) and identified contributory factors for each reported NRE. Clinicians' severity ratings were subjective and based on clinical judgment. When administering the CONES RAs provided examples of severe and non-severe NREs to help clinicians anchor and calibrate their ratings. 
Contributory factors were classified using the following 7 categories: clinical care processes, equipment or supplies, individual factors, environment of care, logistical and system factors, teamwork, and patient factors. Non-routine event counts and the maximum reported NRE severity were computed at the case and perioperative phase level.

Trained RAs used the same CONES to describe reported NREs and to provide their assessment of each NRE's preventability (preventable vs. non-preventable). RA's ratings of preventability were subjective and based on pre-study training that included extensive observations in the NICU and OR, shadowing perioperative providers (e.g., surgeons, CRNAs, NICU nurses, etc.), and case studies of audio and video-recorded episodes of perioperative care that included NREs of variable severity and contributory factors.

\section{Perioperative patient outcomes}

We also collected data on the occurrence of 30-day postoperative major morbidities using the NSQIP-P methodology $[17,18]$. NSQIP-P review was performed by a single surgical resident with training in the NSQIP-P methodology. Thirty-four occurrence types were included in the review-4 intraoperative measures (e.g., cardiac arrest, death, and unplanned extubations) and 30 post-operative measures (e.g., surgical site infections, pneumonia, unplanned intubation, seizure, central line-associated blood stream infection, transfusion, and intraventricular hemorrhage, readmission, and unplanned reoperation among others).

\section{Patient handover perceptions survey}

A 30-item, cross-sectional, web-based survey was developed and administered in the Research Electronic Data Capture (REDCap) program [19] to measure perioperative providers' perceptions and attitudes about current handover practices for surgical neonates (See Table 3). The survey was administered during the 15th month of the 17-month observational study. The survey queries providers about their handover training, handover-related human and system factors, experience with adverse outcomes, handover quality ratings, logistical preferences, and recommendations related to all patient handovers types between the NICU and OR. The survey used the following response formats: Yes/No, multiple choice, 7-point Likert-type scale, and free text.

\section{Statistical analysis}

Descriptive statistics, including percentages for categorical variables and mean and $95 \%$ confidence intervals for continuous variables, were computed for independent and dependent variables. Median and interquartile ranges were computed for NRE count and severity per case, which were both non-normally distributed. We used the Kruskal-Wallis $\mathrm{H}$ test and Dunn's test for post hoc pairwise comparisons to compare patient demographics, clinical, procedural factors, and patient safety metrics (e.g., NREs and 30-day NSQIP-P occurrences) by handover type. An alpha level of 0.05 was used as the cut-off for statistical significance in all analyses. All statistical analyses were conducted in IBM SPSS 25.0 (IBM Corp. Released 2017. IBM SPSS Statistics for Windows, Version 25.0. Armonk, NY: IBM Corp.)

\section{Results}

A total of 312 eligible cases occurred during the study period. One hundred forty-five eligible cases (46\%) could not be observed due to logistical constraints (e.g., late night or weekend cases, concurrent cases, insufficient notice, etc.). In 31 eligible cases (10\%), parents or guardians were unavailable to provide consent. Pediatric surgeons declined to consent in $6(2 \%)$ of eligible cases. No parents or legal guardians declined consent. Thus, we report on 130 cases involving 109 eligible neonates.

A total of 232 providers associated with eligible cases consented to participate in the observational study. Ninetyfour providers (60 from the NICU and 34 from the OR) completed the REDCap survey.

\section{Patient demographics, clinical, and procedural factors by handover type}

Table 1 presents patient demographics and clinical and procedural characteristics stratified by handover type. Patients receiving direct handovers were sicker and more medically complex than patients transferred by indirect and mixed handovers. Patients receiving direct handovers were more likely to require pre-procedural ventilation $(p<$ 0.001), received higher American Society of Anesthesiologist (ASA) physical status classification scores $(p<0.001)$ from anesthesia providers, and have emergency surgeries $(p=0.016)$ than infants transferred by other handover methods.

\section{Handover effectiveness}

Using the Global Rating of Handover Effectiveness tool, $82 \%(n=39)$ of observed direct NICU-to-OR handovers and $89 \%(n=28)$ of observed direct OR-to-NICU handovers achieved an effectiveness rating $\geq 3$ (5: most effective) indicating that all critical content related to the infant's health status and operative plan was presented and discussed by the perioperative team during the structured handover. 
Table 1 Patient demographics, clinical, and procedural factors by handover type

\begin{tabular}{|c|c|c|c|c|}
\hline \multirow[b]{2}{*}{ Variables } & \multicolumn{4}{|c|}{ Patient handover type } \\
\hline & $\begin{array}{l}\text { Direct } \\
(n=57)\end{array}$ & $\begin{array}{l}\text { Non-direct } \\
(n=61)\end{array}$ & $\begin{array}{l}\text { Mixed } \\
(n=12)\end{array}$ & $\begin{array}{l}\text { Total } \\
(n=130)\end{array}$ \\
\hline Male sex & $53 \%$ & $53 \%$ & $33.3 \%$ & $51 \%$ \\
\hline Caucasian & $70 \%$ & $87 \%$ & $75 \%$ & $79 \%$ \\
\hline Ethnicity (Non-Hispanic) & $90 \%$ & $90 \%$ & $83.3 \%$ & $88 \%$ \\
\hline Weight (Kg) & $3.1(2.8,3.4)$ & $3.4(3.2,3.6)$ & $2.7(2.2,3.4)$ & $3.2(3.1,3.4)$ \\
\hline Gestational age at birth (weeks) & $\begin{array}{l}33(32.2 \\
34.4)\end{array}$ & $\begin{array}{l}33.8(32.3 \\
35.3)\end{array}$ & $\begin{array}{l}32.9(29.4 \\
36.3)\end{array}$ & $\begin{array}{l}33.4(32.4 \\
34.3)\end{array}$ \\
\hline $\begin{array}{l}\text { Postnatal age at surgical procedure } \\
\text { (days) }\end{array}$ & $56(37,75)$ & $54(41,67)$ & $49(14,84)$ & $55(44,65)$ \\
\hline Pre-procedural ventilator support & $90 \%$ & $23 \%$ & $42 \%$ & $54 \%$ \\
\hline Inhaled nitic oxide & $5 \%$ & - & - & $2 \%$ \\
\hline Extracorporeal membrane oxygenation & $4 \%$ & - & - & $2 \%$ \\
\hline \multicolumn{5}{|l|}{ Anesthetic } \\
\hline General & $98 \%$ & $89 \%$ & $92 \%$ & $93 \%$ \\
\hline General with regional & $2 \%$ & $11 \%$ & $8 \%$ & $7 \%$ \\
\hline ASA score & $3.4(3.2,3.6)^{\dagger}$ & $3.1(2.9,3.2)^{\dagger}$ & $3.1(2.8,3.4)$ & $3.2(3.1,3.3)$ \\
\hline \multicolumn{5}{|l|}{ Surgical specialty } \\
\hline General surgery & $60 \%$ & $79 \%$ & $75 \%$ & $70 \%$ \\
\hline Otolaryngology & $28 \%$ & $3 \%$ & $8 \%$ & $15 \%$ \\
\hline Neurosurgery & $9 \%$ & $8 \%$ & - & $8 \%$ \\
\hline Ophthalmology & - & $3 \%$ & $17 \%$ & $3 \%$ \\
\hline Plastic & - & $2 \%$ & - & $1 \%$ \\
\hline Urology & $3 \%$ & $5 \%$ & - & $4 \%$ \\
\hline Emergency surgery & $26 \%{ }^{\dagger}$ & $7 \%$ & $17 \%$ & $16 \%$ \\
\hline $\begin{array}{l}\text { Procedures per case (mean number, } \\
95 \% \text { CI) }\end{array}$ & $2.0(1.7,2.2)$ & $1.9(1.7,2.2)$ & $2.1(1.4,2.8)$ & $2.0(1.8,2.1)$ \\
\hline
\end{tabular}

\section{Non-routine events by handover type}

Table 2 presents the incidence and severity of clinicianreported NREs, NRE preventability ratings assessed by trained RAs, and NSQIP-P occurrence rates for surgical neonates stratified by case handover type. Non-routine events were reported by clinicians in 101/130 (78\%) cases but did not differ significantly by handover practices $(p=$ 0.790). The incidence of preventable and preventable, severe NREs did not differ significantly by handover $(p=$ $0.375)$. Maximum NRE severity (per case) was significantly higher $(p=0.009)$ in cases with direct handovers and mixed handovers compared to cases with indirect handovers.

At the NRE level, clinicians rated $28 \%$ of all NREs as severe and trained RAs rated $47 \%$ of reported NREs as preventable. Eleven percent of severe NREs were preventable. NRE severity and preventability did not vary significantly by handover type.

Table 3 shows the distribution of the primary factors that contributed to clinician-reported NREs. Patient factors were the most frequently reported contributors to NREs. Clinical care processes and equipment issues were the most frequently cited preventable contributory factors. Teamwork was more frequently a factor in team-based handovers (direct and mixed) than indirect handovers.

Table 4 provides examples of clinician-reported NREs along with their primary contributory factor and severity score, and RA-assessed preventability determination for direct, indirect, and mixed handovers, respectively.

\section{NSQIP-P occurrences by handover type}

The incidence of major morbidities (28\% overall), as defined by NSQIP-P, was significantly higher $(p<0.001)$ in cases with direct team handovers than those with indirect or mixed handovers (Table 2). Cases with direct handovers also accounted for a significantly higher mean count of NSQIP-P occurrences per NRE case. Transfusions $(n=12$, $32 \%)$, reintubations $(n=11,30 \%$, post-operative deaths $(n=4,11 \%$, and post-operative cardiac arrests $(n=2,5 \%)$ accounted for nearly $80 \%$ of the observed NSQIP-P occurrences in the study sample. 
Table 2 Patient safety outcomes by handover type

\begin{tabular}{|c|c|c|c|c|}
\hline \multirow[b]{2}{*}{ Dependent variable (percent or mean) } & \multicolumn{4}{|c|}{ Patient handover type } \\
\hline & Direct $(n=57)$ & Non-direct $(n=61)$ & Mixed $(n=12)$ & Total $(n=130)$ \\
\hline & Percent & Percent & Percent & Percent \\
\hline Cases with $\geq 1 \mathrm{NRE}$ & 79 & 74 & 92 & 78 \\
\hline Cases with $\geq 1$ severe NRE & 25 & 13 & 17 & 19 \\
\hline Cases with $\geq 1$ preventable severe NRE & 25 & 19 & 33 & 28 \\
\hline Cases with $\geq 1$ NSQIP-P occurrence & $44^{\dagger \dagger}$ & 16 & 8 & 28 \\
\hline NRE cases ( $\geq 1$ NRE) with NSQIP-P occurrence & $49^{\dagger \dagger}$ & 16 & 9 & 30 \\
\hline \multirow[t]{2}{*}{ Cases with one or more NREs } & Direct $(n=45)$ & Non-direct $(n=45)$ & Mixed $(n=11)$ & Total $(n=101)$ \\
\hline & Mean $(95 \% \mathrm{CI})$ & Mean $(95 \% \mathrm{CI})$ & Mean $(95 \% \mathrm{CI})$ & Mean $(95 \% \mathrm{CI})$ \\
\hline NREs per case & $2.5(2.0,3.0)$ & $2.5(2.0,2.9)$ & $2.1(1.3,2.9)$ & $2.4(2.1,2.7)$ \\
\hline Maximum NRE Severity per case & $2.8(2.4,3.2)$ & $2.6(2.3,2.9)$ & $2.9(1.9,3.9)$ & $2.7(2.5,3.0)$ \\
\hline NSQIP occurrences per case & $0.6(0.4,0.9)^{\dagger \dagger}$ & $0.2(0.0,0.4)$ & $0.10(0.0,0.4)$ & $0.4(0.3,0.5)$ \\
\hline Pre-operative NREs & $1.1(0.9,1.2)$ & $1.1(0.9,1.2)$ & $1.2(0.7,1.6)$ & $1.1(1.0,1.2)$ \\
\hline Operative NREs & $1.6(1.4,1.9)$ & $1.9(1.6,2.3)$ & $1.6(1.1,2.1)$ & $1.8(1.6,2.0)$ \\
\hline Early post-operative NREs & $1.5(0.9,2.1)$ & $1.5(0.6,2.4)$ & None & $1.5(1.0,2.0)$ \\
\hline Late post-operative NREs & $1.9(1.2,2.6)$ & $1.8(0.9,2.6)$ & $1.0(1.0,1.0)$ & $1.8(1.3,2.2)$ \\
\hline Pre-operative maximum NRE severity & $3.0^{\dagger}(2.2,3.8)$ & $1.8(1.3,2.4)$ & $3.5^{\dagger}(0,9.9)$ & $2.5(2.0,2.9)$ \\
\hline Operative maximum NRE severity & $2.3(1.9,2.8)$ & $2.6(2.3,3.0)$ & $2.5(1.4,3.6)$ & $2.5(2.2,2.7)$ \\
\hline Early post-operative maximum NRE severity & $2.5(1.4,3.6)$ & $2.6(0.7,4.5)$ & None & $2.6(1.7,3.4)$ \\
\hline Late post-operative maximum NRE severity & $3.2(2.3,2.3)$ & $2.6(1.4,3.8)$ & $2.0(0.0,14.7)$ & $2.8(2.2,3.5)$ \\
\hline
\end{tabular}

${ }^{\dagger} p<0.05 ;{ }^{\dagger} p<0.01$

\section{Patient handover perceptions survey}

The Handover Perceptions Survey (Table 5) was completed by 96 neonatal perioperative providers $(15 \%$ of all total providers and approximately $40 \%$ of observed providers). For the purpose of this initial analysis anesthesia providers were classified as OR providers. Of the respondents $80 \%$ had received prior handover training. A significantly higher proportion of OR providers had received handover training than NICU providers. NICU and OR teams had significantly different perspectives on the type of providers who should be present at standardized, face-to-face patient handovers. Thirty-seven percent of NICU providers and $18 \%$ of OR providers reported that a poor handover had resulted in a serious adverse outcome in a prior patient. NICU and OR providers rated direct handovers as critical to patient safety and indicated low confidence that patient safety could be maximized without them. All perioperative providers preferred face-to-face interdisciplinary handovers over one-on-one and electronic handovers, and they preferred to be present in handovers involving their patients. However, a significantly higher proportion of OR providers than NICU providers responded that they routinely attend direct pre-operative and post-operative handovers. However, these behaviors were not routinely observed in practice during observed cases. A significantly higher proportion of NICU providers stated that direct handovers interfere with other clinical tasks and expressed dissatisfaction with the communication related to the timing of handovers. OR providers were significantly more satisfied with the quality of direct handovers to and from the OR than NICU providers. NICU and OR providers both agreed that there was a moderate to critical need for structured handovers between the NICU and holding room and the PACU and the NICU. Finally, NICU and OR providers demonstrated agreement that the most important information they seek and provide during handovers are patient medications, OR events, and respiratory and airway support.

\section{Discussion}

The incidence of clinician-reported NREs was high in our observational study of neonatal perioperative care, with $78 \%$ of observed cases having an NRE and $30 \%$ having a severe NRE. Trained RAs determined that nearly half of NREs resulted from preventable factors and preventablesevere NREs occurred in 1 of 9 surgical cases. Interestingly, unadjusted NRE rates did not differ significantly by handover type despite direct handovers being used in the most critically ill patients. Cases that included team-based handovers (i.e., direct or mixed handovers) were 
associated with higher NRE severity and higher rates of NSQIP-P occurrences, the only outcomes associated with handover types in unadjusted analyses. These findings are not surprising given that patients who receive structured team-based handovers in our hospital are the most acutely ill, clinically complex, and, from a surgical perspective, often the most technically complicated.

We were unable to quantify the safety benefit team-based handovers provided to high-acuity cases because preintervention NRE rates and NSQIP-P occurrence rates were not know prior to the adoption of interdisciplinary face-to-face handoffs. However, the homogeny of NRE rates across handover types provides evidence that structured, team-based handovers provide a protective benefit to iatrogenic patient safety events, such as NREs in the 24-h post-operative period. Additional research is needed to determine the relative contributions of mutable human and system factors versus underlying health status to neonatal perioperative risk and to quantify the short-term (i.e., up to $24 \mathrm{~h}$ post-operative) and quasi-long-term (i.e., 30-day postoperative) impact of handover structure on safety outcomes. Pre-post (handover intervention) study designs are needed to accomplish these goals. The study brings to light important findings about the effectiveness, opportunities, and remaining challenges of patient handovers practices to improve patient safety, especially in vulnerable populations.

Our stratified analysis of NRE rates by handover type and our supplementary survey of providers' perceptions highlighted both the advances healthcare organizations have made in standardizing handover processes and barriers remaining in current practice. The results showed that although $82 \%$ of observed structured, face-to-face handovers were rated as either effective or highly effective by trained RAs they did not prevent the occurrence of safety events in clinically high-risk cases. NSQIP-P occurrences were highest in direct handovers. Almost 20\% of contributory factors attributed to NREs in direct and mixed patient handovers (i.e., including structured team handovers) were related to teamwork which highlights the ongoing challenges to align interdisciplinary handover work in the context of the unsynchronized work patterns of the neonatology, anesthesia, and pediatric surgery.

The direct handover process observed during this study is the product of years of rigorous patient safety research and numerous QI initiatives. This work started with the development, training, and evaluation of a multimodal intervention to improve PACU handovers in adult and pediatric units [16], which has recently been adapted to improve preoperative pediatric and neonatal handovers $[20,21]$. The handover work completed at the study hospital is a microcosm of broader international research and QI efforts aimed at eliminating preventable communication errors in healthcare. Communications errors are estimated to 
Table 4 Examples of NREs reported during direct patient handovers

\begin{tabular}{|c|c|c|c|}
\hline NRE description & $\begin{array}{l}\text { Primary contributory } \\
\text { factor }\end{array}$ & Severity $(1-5)$ & Preventable (Yes/No) \\
\hline \multicolumn{4}{|l|}{ Direct handovers } \\
\hline No surgery team representative at handover to discuss surgery details & $\begin{array}{l}\text { Logistical and system } \\
\text { factors }\end{array}$ & 3 & Yes \\
\hline Consent was not at bedside which caused a delay & Clinical processes & 5 & Yes \\
\hline $\begin{array}{l}\text { Call from OR to NICU said they would arrive in the afternoon based on } \\
\text { ECMO availability, but arrived shortly after making the phone call to pick up } \\
\text { patient. Nurse didn't have time to prepare patient and caused delay }\end{array}$ & Teamwork & 3 & Yes \\
\hline Loud and lots of side conversations during return handover & Environment of care & 1 & Yes \\
\hline Bronchospasms/apnea, desaturated to the 60 's & Equipment or supplies & 3 & No \\
\hline Emergent bedside procedure for post-operative hemorrhaging & Patient factors & 4 & No \\
\hline \multicolumn{4}{|l|}{ Indirect handovers } \\
\hline $\begin{array}{l}\text { Holding nurse did not complete patient's chart so circulator was unable to } \\
\text { record }\end{array}$ & Clinical care processes & 1 & Yes \\
\hline No page to NICU team that patient had returned from surgery & Teamwork & 2 & Yes \\
\hline $\begin{array}{l}\text { Medications left in the medication administration record post-operatively; } \\
\text { NICU nurses unsure if they had been administered or not }\end{array}$ & Clinical care processes & 5 & Yes \\
\hline Mild desaturation during intubation & Patient factors & 3 & No \\
\hline IV placed by anesthesia not flushing and had to be removed post-op & Equipment or supplies & 2 & No \\
\hline Surgery fellow paged for level 1 trauma and had to leave mid-procedure & $\begin{array}{l}\text { Logistical or system } \\
\text { factors }\end{array}$ & 2 & No \\
\hline \multicolumn{4}{|l|}{ Mixed handovers } \\
\hline Equipment not readily available-in different OR than usual & Equipment or supplies & 1 & Yes \\
\hline Delay waiting for surgeon and family to come to bedside to proceed to OR & Teamwork & 1 & Yes \\
\hline $\begin{array}{l}\text { Near-code, laryngospasm during emergence (anesthesia fellow reported } \\
\text { preventable due to time pressures) }\end{array}$ & Clinical care processes & 4 & Yes \\
\hline $\begin{array}{l}\text { Unable to extubate in OR because patient was too apneic, returned to NICU } \\
\text { directly }\end{array}$ & Patient factors & 1 & No \\
\hline Unable to place Foley due to patient anatomy & Patient factors & 2 & No \\
\hline Re-intubated in NICU post-op & Patient factors & 1 & No \\
\hline
\end{tabular}

account for $70 \%$ of preventable medical errors; half of which occur during patient handovers [22, 23]. Significant strides have been made to address this problem, most notably in post-operative handovers, where standardization and customization (i.e., to the unit and needs of the specific patient population) has resulted in increased provider satisfaction, improved teamwork and work efficiency, higher quality clinical communications, error reduction, and better patient outcomes [4, 24]. Preoperative handovers have been much less studied and published intervention studies with patient-specific outcomes are nearly nonexistent [24]. Published research suggests that preoperative handovers share the same shortcomings as their post-operative counterparts and should also benefit from standardized customizable protocols. For example, research conducted in our NICU before the modification and adoption of the direct pre-operative handover protocol found "lack of a standardized report, patients not prepared for transfer, unclear transition of care between team members, unclear provider roles, provider traffic, and distractions" [20, 24]. In consideration of the NRE statistics reported in the results, incorporating NRE reporting and NRE discussions into handover processes represents promising opportunities to improve the detection and clinical response to safety events through handover design. The direct handovers observed in the study included discussions of serious pre-operative and intraoperative events but they did not formally or routinely address low severity NREs. The direct handover protocol was not modified to address NREs for the observational study because its objective was to identify and define the spectrum of neonatal safety risks in the context of existing, unmodified care processes rather than to intervene on suspected risks. Adding a discussion of NREs to all handover processes is highly recommended as a means to promote the generation of a shared mental model of the risks and threats to patient safety between giving and receiving care teams. Raising clinicians' awareness to the occurrence and/or risk of NREs, regardless of 
Table 5 Handover of surgical neonates: providers' perspectives survey (Percentages correspond to bolded response options)

\begin{tabular}{|c|c|c|c|c|}
\hline Number & Survey item & Response options & $\mathrm{NICU}(n=60)$ & OR $(n=34)$ \\
\hline 1 & $\begin{array}{l}\text { Please select your job } \\
\text { category (select one) }\end{array}$ & $\begin{array}{l}\text { - Attending } \\
\text { Anesthesiology } \\
\text { - CRNA } \\
\text { - Anesthesiology Resident } \\
\text { - Attending Neonatologist } \\
\text { - Neonatology Fellow } \\
\text { - NICU RN } \\
\text { - NICU NP (NNP) } \\
\text { - Attending Surgeon } \\
\text { - Surgery Fellow } \\
\text { - Circulating Nurse } \\
\text { - Other }\end{array}$ & $30 \%$ & $16 \%$ \\
\hline 2 & $\begin{array}{l}\text { I have received handover } \\
\text { training (training on the } \\
\text { preferred content, structure } \\
\text { and/or communication flow of } \\
\text { a patient handover). }\end{array}$ & $\begin{array}{l}\cdot \mathrm{YES} \\
\cdot \mathrm{NO}\end{array}$ & $72 \%$ & $91 \% *$ \\
\hline 3 & $\begin{array}{l}\text { My department or division } \\
\text { encourages my presence at } \\
\text { patient handovers between the } \\
\text { NICU and OR (vice versa)? }\end{array}$ & $\begin{array}{l}-\mathrm{YES} \\
\cdot \mathrm{NO}\end{array}$ & $97 \%$ & $91 \%$ \\
\hline 4 & $\begin{array}{l}\text { Every DIRECT handover } \\
\text { should require the presence of } \\
\text { (check all that apply): }\end{array}$ & $\begin{array}{l}\text { - Anesthesiologist } \\
\text { - CRNA } \\
\text { - Anesthesia Resident } \\
\text { - Neonatologist } \\
\text { - Neonatology Fellow } \\
\text { - NICU RN } \\
\text { - NICU NP (NNP) } \\
\text { - Attending Surgeon } \\
\text { - Surgery Fellow } \\
\text { - Circulating Nurse } \\
\text { - Charge nurse } \\
\text { - Respiratory therapy } \\
\text { - Family or Guardian }\end{array}$ & $\begin{array}{l}37 \% \\
75 \% \\
68 \% \\
32 \% \\
88 \% * * \\
97 \% \\
77 \% \\
12 \% \\
58 \% \\
40 \% \\
5 \% \\
82 \% * \\
58 \%\end{array}$ & $\begin{array}{l}77 \% * * \\
91 \% * \\
47 \% \\
53 \% \\
62 \% \\
88 \% \\
59 \% \\
21 \% \\
50 \% \\
88 \% * * \\
3 \% \\
53 \% \\
44 \%\end{array}$ \\
\hline 5 & $\begin{array}{l}\text { My presence is critical for } \\
\text { every DIRECT handover } \\
\text { involving my patients? }\end{array}$ & $\begin{array}{l}\text { YES } \\
\text { NO }\end{array}$ & $85 \%$ & $84 \%$ \\
\hline 6 & $\begin{array}{l}\text { In my experience with } \\
\text { DIRECT handovers, I receive } \\
\text { information that causes me to } \\
\text { modify the subsequent plan of } \\
\text { care for a given patient. }\end{array}$ & $\begin{array}{l}\text { 1: Never } \\
\text { 2: Almost never } \\
\text { 3 Infrequently } \\
\text { 4: Occasionally } \\
\text { 5: Frequently } \\
\text { 7: Almost always } \\
\text { 8: Always }\end{array}$ & $44 \%$ & $39 \%$ \\
\hline 7 & $\begin{array}{l}\text { During my DIRECT } \\
\text { handovers, I provide } \\
\text { information that results in the } \\
\text { modification of the } \\
\text { subsequent plan of care for a } \\
\text { given patient. }\end{array}$ & $\begin{array}{l}\text { 1: Never } \\
\text { 2: Almost never } \\
\text { 3 Infrequently } \\
\text { 4: Occasionally } \\
\text { 5: Frequently } \\
\text { 7: Almost always } \\
\text { 8: Always }\end{array}$ & $31 \%$ & $46 \%$ \\
\hline 8 & $\begin{array}{l}\text { A poor patient handover } \\
\text { (rushed, unorganized, missing } \\
\text { critical info, etc.) has resulted } \\
\text { in serious adverse events in a } \\
\text { child I provided care for (e.g., } \\
\text { serious operative or post- } \\
\text { operative complications, } \\
\text { unplanned return to the OR, }\end{array}$ & $\begin{array}{l}\cdot \text { YES } \\
\cdot \text { NO }\end{array}$ & $37 \% *$ & $18 \%$ \\
\hline
\end{tabular}


Table 5 (continued)

\begin{tabular}{|c|c|c|c|c|}
\hline Number & Survey item & Response options & $\mathrm{NICU}(n=60)$ & OR $(n=34)$ \\
\hline 9 & $\begin{array}{l}\text { prolonged length of stay, } \\
\text { death). } \\
\text { My participation in face-to- } \\
\text { face handovers is MOST } \\
\text { critical for: }\end{array}$ & $\begin{array}{l}\text { DIRECT NICU-to-OR } \\
\text { handovers } \\
\text { DIRECT OR-to-NICU } \\
\text { handovers } \\
\text { Both handovers: My } \\
\text { participation is critical for } \\
\text { both handovers } \\
\text { Neither handover: My } \\
\text { participation is not critical } \\
\text { for either handover }\end{array}$ & $83 \%$ & $74 \%$ \\
\hline 10 & $\begin{array}{l}\text { My participation in face-to- } \\
\text { face handovers is LEAST } \\
\text { critical for: }\end{array}$ & $\begin{array}{l}\text { DIRECT NICU-to-OR } \\
\text { handovers } \\
\text { DIRECT OR-to-NICU } \\
\text { handovers } \\
\text { BOTH: My participation } \\
\text { is not critical for either } \\
\text { handover } \\
\text { NEITHER: My } \\
\text { participation is critical for } \\
\text { both handovers }\end{array}$ & $85 \%$ & $68 \%$ \\
\hline 11 & $\begin{array}{l}\text { If given the choice, the mode } \\
\text { of handover communications } \\
\text { I would MOST prefer for } \\
\text { Direct handovers is? }\end{array}$ & a. & $\begin{array}{l}\text { Face-to-face TEAM } \\
\text { handover (i.e., various } \\
\text { providers meeting together } \\
\text { in the NICU) } \\
\text { b.Face-to-face } \\
\text { INDIVIDUAL } \\
\text { communications (i.e., One- } \\
\text { on-one handovers: surgeon- } \\
\text { neonatologist, NICU RN- } \\
\text { anesthesia provider) } \\
\text { c.Telephone-based } \\
\text { handovers } \\
\text { d.Electronic handover (i.e., } \\
\text { EMR notes and messaging) }\end{array}$ & $95 \%$ \\
\hline 12 & $\begin{array}{l}\text { I typically conduct handover } \\
\text { communications for } \\
\text { scheduled neonatal } \\
\text { operations: }\end{array}$ & a. & $\begin{array}{l}\text { The day or night before the } \\
\text { case } \\
\text { b.Same day as case, before } \\
\text { the team handover } \\
\text { c.During the team handover } \\
\text { in the NICU } \\
\text { d.Not at all }\end{array}$ & $60 \%$ \\
\hline 13 & $\begin{array}{l}\text { If given the choice, I would } \\
\text { like to conduct handover } \\
\text { communications for } \\
\text { scheduled neonatal } \\
\text { operations: }\end{array}$ & a. & $\begin{array}{l}\text { The day or night before the } \\
\text { case } \\
\text { b.Same day as case, before } \\
\text { the team handover } \\
\text { c.During the team handover } \\
\text { in the NICU } \\
\text { d.Not at all }\end{array}$ & $60 \%$ \\
\hline 14 & $\begin{array}{l}\text { I attend pre-operative } \\
\text { handovers for DIRECT cases: }\end{array}$ & $\begin{array}{l}\text { 1: Never } \\
\text { 2: Almost Never } \\
\text { 3 Infrequently } \\
\text { 4: Occasionally } \\
\text { 5: Frequently } \\
\text { 6: Almost always } \\
\text { 7: Always }\end{array}$ & $67 \%$ & $94 \% * *$ \\
\hline 15 & $\begin{array}{l}\text { I attend post-operative } \\
\text { handovers for DIRECT cases: }\end{array}$ & $\begin{array}{l}\text { 1: Never } \\
\text { 2: Almost never }\end{array}$ & $73 \%$ & $82 \% * *$ \\
\hline
\end{tabular}


Table 5 (continued)

\begin{tabular}{|c|c|c|c|c|}
\hline Number & Survey item & Response options & $\mathrm{NICU}(n=60)$ & OR $(n=34)$ \\
\hline 16 & $\begin{array}{l}\text { The criticality/importance of } \\
\text { face-to-face handovers for } \\
\text { DIRECT handovers from the } \\
\text { NICU to the OR for patient } \\
\text { safety? }\end{array}$ & $\begin{array}{l}\text { 3 Infrequently } \\
\text { 4: Occasionally } \\
\text { 5: Frequently } \\
\text { 6: Almost always } \\
\text { 7: Always } \\
\text { 1: Not at all critical } \\
\text { 2: Low criticality } \\
\text { 3 Slightly critical } \\
\text { 4: Neutral } \\
\text { 5: Moderately critical } \\
\text { 6: Very critical } \\
\text { 7: Extremely critical }\end{array}$ & $87 \%$ & $90 \%$ \\
\hline 17 & $\begin{array}{l}\text { The criticality/importance of } \\
\text { face-to-face handovers for } \\
\text { DIRECT handovers from the } \\
\text { OR to the NICU for patient } \\
\text { safety? }\end{array}$ & $\begin{array}{l}\text { 1: Not at all critical } \\
\text { 2: Low criticality } \\
\text { 3 Slightly critical } \\
\text { 4: Neutral } \\
\text { 5: Moderately critical } \\
\text { 6: Very critical } \\
\text { 7: Extremely critical }\end{array}$ & $93 \%$ & $94 \%$ \\
\hline 18 & $\begin{array}{l}\text { My confidence that patient } \\
\text { safety can be maintained } \\
\text { without requiring structured } \\
\text { team handovers between the } \\
\text { NICU and OR? }\end{array}$ & $\begin{array}{l}\text { 1: No confidence } \\
\text { 2: Very low confidence } \\
3 \text { Slightly low confidence } \\
\text { 4: Moderate confidence } \\
\text { 5: Slightly high } \\
\text { confidence } \\
\text { 6: Very high confidence } \\
\text { 7: Complete confidence }\end{array}$ & $5 \%$ & $6 \%$ \\
\hline 19 & $\begin{array}{l}\text { DIRECT NICU-to-OR } \\
\text { handovers interrupt other } \\
\text { required work (e.g., patient } \\
\text { care, rounding, teaching, etc.). }\end{array}$ & $\begin{array}{l}\text { 1: Never interrupts } \\
\text { 2: Rarely interrupts }(10 \% \\
\text { of time) } \\
3 \text { Occasionally interrupts } \\
\text { (30\% of time) } \\
\text { 4: Sometimes interrupts } \\
\text { (50\% of time) } \\
\text { 5: Frequently interrupts } \\
\text { (70\% of time) } \\
\text { 6: Usually interrupts } \\
\text { (90\%) } \\
7: \text { Always interrupts }\end{array}$ & $38 \% *$ & $30 \%$ \\
\hline 20 & $\begin{array}{l}\text { DIRECT OR-to-NICU } \\
\text { handovers interrupt other } \\
\text { required work (e.g., patient } \\
\text { care, rounding, teaching, etc.) }\end{array}$ & $\begin{array}{l}\text { 1: Never interrupts } \\
\text { 2: Rarely interrupts }(10 \% \\
\text { of time) } \\
3 \text { Occasionally interrupts } \\
\text { (30\% of time) } \\
\text { 4: Sometimes interrupts } \\
\text { (50\% of time) } \\
\text { 5: Frequently interrupts } \\
\text { (70\% of time) } \\
6: \text { Usually interrupts } \\
\text { (90\%) } \\
7: \text { Always interrupts }\end{array}$ & $37 \% * *$ & $18 \%$ \\
\hline 21 & $\begin{array}{l}\text { My likelihood of attending } \\
\text { my patients' NICU-to-OR } \\
\text { handovers for DIRECT cases } \\
\text { if free of competing } \\
\text { priorities? }\end{array}$ & $\begin{array}{l}\text { 1: Least likely } \\
\text { 2: Unlikely } \\
\text { 3 Slightly less likely } \\
\text { 4: Moderately likely } \\
\text { 5: Slightly more likely } \\
\text { 6: Likely } \\
\text { 7: Most likely }\end{array}$ & $80 \%$ & $82 \%$ \\
\hline
\end{tabular}


Table 5 (continued)

\begin{tabular}{|c|c|c|c|c|}
\hline Number & Survey item & Response options & $\mathrm{NICU}(n=60)$ & OR $(n=34)$ \\
\hline 22 & $\begin{array}{l}\text { My likelihood of attending } \\
\text { my patients' OR-to-NICU } \\
\text { handovers for DIRECT cases } \\
\text { if free of competing } \\
\text { priorities? }\end{array}$ & $\begin{array}{l}\text { 1: Least likely } \\
\text { 2: Unlikely } \\
\text { 3 Slightly less likely } \\
\text { 4: Moderately likely } \\
\text { 5: Slightly more likely } \\
\text { 6: Likely } \\
\text { 7: Most likely }\end{array}$ & $81 \%$ & $81 \%$ \\
\hline 23 & $\begin{array}{l}\text { My satisfaction with the } \\
\text { timing of communications } \\
\text { related to patient handovers } \\
\text { (i.e., do you have ample } \\
\text { warning that a patient transfer } \\
\text { is going to occur)? }\end{array}$ & $\begin{array}{l}\text { 1: Completely dissatisfied } \\
\text { 2: Mostly dissatisfied } \\
\text { 3: Somewhat dissatisfied } \\
\text { 4: Neither satisfied or } \\
\text { dissatisfied } \\
\text { 5: Somewhat satisfied } \\
\text { 6: Mostly satisfied } \\
\text { 7: Completely satisfied }\end{array}$ & $41 \%$ & $79 \% * *$ \\
\hline 24 & $\begin{array}{l}\text { The current quality of } \\
\text { DIRECT NICU-to-OR } \\
\text { handovers? }\end{array}$ & $\begin{array}{l}\text { 1: Poorest quality } \\
\text { 2: Low quality } \\
\text { 3: Slightly low quality } \\
\text { 4: Adequate quality } \\
\text { 5: Slightly high quality } \\
\text { 6: Very high quality } \\
\text { 7: Highest quality }\end{array}$ & $47 \%$ & $57 \% *$ \\
\hline 25 & $\begin{array}{l}\text { The quality of DIRECT OR- } \\
\text { to-NICU handovers? }\end{array}$ & $\begin{array}{l}\text { 1: Poorest quality } \\
\text { 2: Low quality } \\
\text { 3: Slightly low quality } \\
\text { 4: Adequate quality } \\
\text { 5: Slightly high quality } \\
\text { 6: Very high quality } \\
\text { 7: Highest quality }\end{array}$ & $37 \%$ & $79 \% * *$ \\
\hline 26 & $\begin{array}{l}\text { The need for structured } \\
\text { handovers for patient transfers } \\
\text { from the NICU to the Holding } \\
\text { Room (Indirect handovers) }\end{array}$ & $\begin{array}{l}\text { 1: No need } \\
\text { 2: Very low need } \\
\text { 3: Low need } \\
\text { 4: Neutral } \\
\text { 5: Moderate need } \\
\text { 6: High need } \\
\text { 7: Critical need }\end{array}$ & $75 \%$ & $79 \%$ \\
\hline 27 & $\begin{array}{l}\text { The need for structured } \\
\text { handovers for patient transfers } \\
\text { from the PACU to the NICU } \\
\text { (Indirect Handovers)? }\end{array}$ & $\begin{array}{l}\text { 1: No need } \\
\text { 2: Very low need } \\
\text { 3: Low need } \\
\text { 4: Neutral } \\
\text { 5: Moderate need } \\
\text { 6: High need } \\
\text { 7: Critical need }\end{array}$ & $83 \%$ & $75 \%$ \\
\hline 28 & $\begin{array}{l}\text { What is the most critical } \\
\text { information I typically } \\
\text { PROVIDE at a patient } \\
\text { handover? }\end{array}$ & Free text response & $\begin{array}{l}\text { Medications } 16 \% \\
\text { OR Events } 15 \% \\
\text { Resp./Airway Support } 13 \%\end{array}$ & \\
\hline 29 & $\begin{array}{l}\text { What is the most critical } \\
\text { information I SEEK TO } \\
\text { OBTAIN at a patient } \\
\text { handover? }\end{array}$ & Free text response & $\begin{array}{l}\text { Resp./Airway Support } 20 \% \\
\text { Medications } 19 \% \\
\text { OR Events } 13 \%\end{array}$ & \\
\hline 30 & $\begin{array}{l}\text { Please add additional } \\
\text { comments you may have } \\
\text { about patient handovers }\end{array}$ & Free text response & $\begin{array}{l}\text { Need PACU-NICU } \\
\text { Handover } \\
\text { Improve handover culture } \\
\text { Earlier postop notice to } \\
\text { NICU }\end{array}$ & \\
\hline
\end{tabular}

$* p<0.05 ; * * p<0.01$ 
their severity or preventability, may circumvent subsequent related NREs and mitigate the impact of NREs on patient outcomes.

Unstructured nursing handovers between the NICU and holding room or PACU "get the job done" for lower risk infants in that they do not elevate safety risk in clinically lower risk cases relative to other handover types, but for the reasons described above, are far from optimal. Our observational data and our moderate sample of perioperative providers' survey responses painted a picture of the complex state of neonatal handovers at the study hospital. Because the hospital uses a mixture of handover structures and processes, the results, while not representative of global handover practices, are effective in highlighting the competing cultures of the clinical specialties (e.g., neonatology, anesthesia, and surgery) and the many challenges hospitals face in coordinating neonatal care transitions.

In the study hospital, direct pre-operative handovers that are intended to invite the presence and participation of nurses, surgeons, neonatologists, anesthesia providers, and therapists are primarily used by NICU nurses and the anesthesia providers. Workflow constraints often prevent surgeons from participating in the handover so pre-operative communications between the surgeon, family or guardian, neonatologist, and/or NICU nurse must take place before the structured handover. In contrast to their survey responses indicating the high value of all direct (team) handovers and the criticality of their own participation, neonatologists participate most in post-operative handovers to the NICU. It is at this time when they learn how the infant's clinical status has changed from his or her pre-operative baseline. One explanation for this contradiction is that neonatologist may feel they have little into gain, in terms of information collection, from participating in pre-operative handovers since they know the infants under their care so well, especially in those infants who have had extended lengths-of-stay in the NICU. The challenge here is to emphasize the importance of the neonatologist's role in pre-operative handovers as an information provider to the OR team.

NICU nurses are dissatisfied with the timing (or lack) of communications about an imminent handover from the OR or PACU. The timing of handovers are driven by the OR schedule and thus fit with the anesthesia provider's workflow however they create a disruption to the workflow of all other providers. This is a classic example of what Deming $[25,26]$ called sub-optimization where optimizing one part of the system creates unintended consequences in another part of the system. NICU providers frequently are paged from the bedside of a critically ill infant to attend a handover of a child considered significantly less ill. Further, providers, as demonstrated above in the contrast between the attitudes and behaviors of neonatologists, are more interested in receiving information critical to their work and are less interested in providing information to others. Thus, NICU providers perceive handovers for patients arriving in the NICU from the OR as much more valuable. These findings suggest that a structured daily meeting of anesthesia providers and NICU staff for all handovers of patients scheduled to go to the OR that day might provide less interruption and yield better results.

All clinicians were emphatic in stressing the value of structured handovers in preserving patient safety and the need for the development and implementation of structured handovers for indirect cases. In addition to these findings, it is important to note that the NICU and OR at the study hospital are separated by one floor and almost all operations are performed in the OR. In fact, all of the observed operations were performed in the OR. While NICU-centric surgeries would likely improve the participation in and quality of current handover processes, they would also create new risks to neonatal safety $[25,26]$, again through the process of sub-optimization, by pulling critical resources from other NICU patients, creating distractions for other NICU providers, and creating ergonomic stressors for surgeons, to name a few. The challenge moving forward for handover design in the neonatal perioperative environment is finding solutions that maximize patient safety while remaining flexible to the distinct workflows of neonatology, anesthesia, and surgery.

\section{Limitations}

This study had several limitations. First, NRE reports were undoubtedly influenced by inherent reporter biases because they were submitted by NICU and OR clinicians involved in the care of observed surgical neonates. Second, NRE severity and preventability were subjectively rated and based purely on clinician and RA experience, respectively. For future analyses we will use subject matter experts (i.e., trained clinicians not involved in the care of the observed infants) to perform a secondary, final review to validate these initial ratings. Third, the study had no historical control data to compare NRE incidence and NSQIP-P occurrence rates before the adoption of direct handovers. Finally, due to sample size constraints, we were unable to statistically model the relationship between NRE count or severity and 30-day NSQIP-P occurrences. To address this limitation, we are adding a second children's hospital as a study site to increase our sample size.

\section{Conclusion}

The results reported here represent the practices, behaviors, and attitudes of clinicians at one children's hospital and 
cannot be used to draw broad conclusions on the state of patient handovers in the neonatal perioperative environments. Instead, the study highlights the pressing need in neonatal systems safety research to quantify and qualify the existing variability in patient handover practices across hospitals. Undoubtedly, there are wide distributions in the structures, processes, content, timing, and effectiveness of nursing handovers and interdisciplinary team handovers in use in this domain. Because hospitals, NICUs, and ORs vary in terms of size, patient volume, resources, and acuity level, it is likely to be neither feasible nor practical to design and implement a single solution for handover structure (i.e., interdisciplinary team handover) given these constraints. However, designing and implementing a universal handover process (i.e., content, order, timing, etc.) is feasible and is worthy of pursuit to improve neonatal safety. Therefore, future research is needed to identify an existing or design a new a unifying handover process, identify or design resource-matched structures (i.e., participants and their roles), and to guide their dissemination through the use of implementation science methodologies.

Acknowledgements We greatly appreciate the informatics support Jonathan Wanderer, MD, and the Vanderbilt Anesthesiology \& Perioperative Informatics Research (VAPIR) Division provided in developing an algorithm to automatically identify eligible study patients through the surgical schedule. Funding: This study was supported by funding from the National Institute of Child Health and Human Development (1R01HD086792-01).

Author contributions All of the individuals listed as authors on the title page contributed to the conception, design, and execution of the study plan, contributed to the writing and/or revision of the manuscript, and approved the final version of the manuscript. Each author has had full access to the study data and was involved the final decision to submit these data for publication.

\section{Compliance with ethical standards}

Conflict of interest The authors declare that they have no conflict of interest.

Publisher's note: Springer Nature remains neutral with regard to jurisdictional claims in published maps and institutional affiliations.

\section{References}

1. Patterson ES, Wears RL. Patient handoffs: standardized and reliable measurement tools remain elusive. Jt Comm J Qual Patient Saf. 2010;36:52-61.

2. Catchpole KR, de Leval MR, McEwan A, Pigott N, McQuillan A, MacDonald $\mathrm{C}$, et al. Patient handover from surgery to intensive care: using Formula 1 pit-stop and aviation models to improve safety and quality. Paediatr Anaesth. 2007;17:470-8.

3. Woods DMML. Patient transitions and handovers across the continuum of surgical care. In: Sanchez JBP, Johnson J, Jacobs J, editors. Surgical patient care. Switzerland: Springer International Publishing; 2017.

4. Segall N, Bonifacio AS, Schroeder RA, Barbeito A, Rogers D, Thornlow DK, et al. Can we make postoperative patient handovers safer? A systematic review of the literature. Anesth Analg. 2012;115:102-15.

5. Segall N, Bonifacio AS, Barbeito A, Schroeder RA, Perfect SR, Wright MC, et al. Operating room-to-ICU patient handovers: a multidisciplinary human-centered design approach. Jt Comm J Qual Patient Saf. 2016;42:400-14.

6. Spooner AJ, Aitken LM, Corley A, Fraser JF, Chaboyer W. Nursing team leader handover in the intensive care unit contains diverse and inconsistent content: an observational study. Int J Nurs Stud. 2016;61:165-72.

7. Spooner AJ, Chaboyer W, Corley A, Hammond N, Fraser JF. Understanding current intensive care unit nursing handover practices. Int J Nurs Pract. 2013;19:214-20.

8. Raju TN, Suresh G, Higgins RD. Patient safety in the context of neonatal intensive care: research and educational opportunities. Pediatr Res. 2011;70:109-15.

9. Kaushal R, Bates DW, Landrigan C, McKenna KJ, Clapp MD, Federico $\mathrm{F}$, et al. Medication errors and adverse drug events in pediatric inpatients. JAMA. 2001;285:2114-20.

10. Bucher BT, Duggan EM, Grubb PH, France DJ, Lally KP, Blakely ML.Does the American College of Surgeons National Surgical Quality Improvement Program pediatric provide actionable quality improvement data for surgical neonates? J Pediatr Surg. 2016 Sep;51:1440-4. https://doi.org/10.1016/j.jpedsurg.2016.02. 084 Epub 2016 Mar 10. PMID:27046303.

11. Saito JM, Chen LE, Hall BL, Kraemer K, Barnhart DC, Byrd C, et al. Risk-adjusted hospital outcomes for children's surgery. Pediatrics. 2013;132:e677-688.

12. Bruny JL, Hall BL, Barnhart DC, Billmire DF, Dias MS, Dillon PW, et al. American College of Surgeons National Surgical Quality Improvement Program Pediatric: a beta phase report. J Pediatr Surg. 2013;48:74-80.

13. Oken A, Rasmussen MD, Slagle JM, Jain S, Kuykendall T, Ordonez N, et al. A facilitated survey instrument captures significantly more anesthesia events than does traditional voluntary event reporting. Anesthesiology. 2007;107:909-22.

14. Weinger MB, Slagle J. Human factors research in anesthesia patient safety. Proc AMIA Symp. 2001:756-60. PMID:11825287 PMCID: PMC2243459.

15. Weinger MB, Slagle J, Jain S, Ordonez N. Retrospective data collection and analytical techniques for patient safety studies. J Biomed Inform. 2003;36:106-19.

16. Weinger MB, Slagle JM, Kuntz AH, Schildcrout JS, Banerjee A, Mercaldo ND, et al. A multimodal intervention improves postanesthesia care unit handovers. Anesth Analg. 2015;121:957-71.

17. Raval M, Dillon P, Bruny J, Ko CY, Hall BL, Moss RL, et al. American College of Surgeons National Surgical Quality Improvement Program Pediatric: a phase 1 report. J Am Coll Surg. 2011;212:1-11.

18. Raval MV, Dillon PW, Bruny JL, Ko CY, Hall BL, Moss RL, et al. Pediatric American College of Surgeons National Surgical Quality Improvement Program: feasibility of a novel, prospective assessment of surgical outcomes. J Pediatr Surg. 2011;46:115-21.

19. Harris PA, Taylor R, Thielke R, Payne J, Gonzalez N, Conde JG. Research electronic data capture (REDCap)--a metadata-driven methodology and workflow process for providing translational research informatics support. J Biomed Inform. 2009;42: 377-81.

20. Lorinc ARD, Slagle J, Tice J, France DJ, Weinger MB. Barriers to effective preoperative handover communication in the neonatal intensive care unit. In: Human factors and ergonomics society 
annual meeting. Vol. 58. Patricia R. DeLucia Sage Publishing. Chicago, IL; 2014. p. 1285-9.

21. Lorinc ACC, Sullivan M, Dickert J, Acton M, Baracz A. Pediatric preoperative handovers: does a checklist improve information exchange? American society of anesthesiology annual meeting. Lippincott Williams \& Wilkins, Incorporated. Chicago, IL; 2016.

22. Choromanski D, Frederick J, McKelvey GM, Wang H. Intraoperative patient information handover between anesthesia providers. JBR. 2014;28:383-7.
23. Lane-Fall MB, Brooks AK, Wilkins SA, Davis JJ, Riesenberg LA. Addressing the mandate for hand-off education: a focused review and recommendations for anesthesia resident curriculum development and evaluation. Anesthesiology. 2014;120:218-29.

24. Barbeito A, Agarwala AV, Lorinc A. Handovers in perioperative care. Anesthesiol Clin. 2018;36:87-98.

25. Deming WE. Out of the crisis. Cambridge, MA: MIT Press; 1986.

26. Deming WE. The new economics. Cambridge, MA: MIT Press; 1993. 